\title{
CARLOS MONTAÑO, LA ESCULTURA COMO INTERPRETACIÓN Y USO DEL ESPACIO
}

\section{CARLOS MONTAÑO, SCULPTURE AS INTERPRETATION AND USE OF SPACE}

\author{
Andrés LuQue Teruel \\ Universidad de Sevilla. España \\ ORCID: 0000-0003-3807-9239 \\ luquete@us.es
}

\begin{abstract}
El artículo analiza la escultura de Carlos Montaño, pintor y escultor sevillano alternativo actual, que ha desarrollado durante décadas un estilo personal, atento a ciertos estímulos internacionales y a la idea renovada de modernidad en las distintas épocas que le tocó vivir. Su independencia y la personalidad de sus planteamientos le proporcionan un gran interés en un contexto amplio y rico en expresiones, que adquieren mayor interés aún con el trasfondo conceptual que lo fundamenta y la obra inédita que damos a conocer. Descifrarlo es necesario para una correcta interpretación de los grupos y estatuas en los que representó desnudos masculinos o cabezas desgajadas, con las que siempre modificó un espacio acercándose al género de la instalación; o lo determinó implicando al espectador por medio de las actitudes, las miradas y los elementos complementarios que portan.

Palabras claves: Carlos Montaño; pintura; escultura; vanguardias; arte conceptual.
\end{abstract}

The paper analyzes the sculpture of Carlos Montaño, current alternative Sevillian painter and sculptor, who has developed for decades a personal style, attentive to certain international stimuli and to the renewed idea of modernity in the different periods that he had to live. His independence and the freedom of his approaches provide him with great interest in a broad context and rich in expressions, which acquire greater interest even with the conceptual background that underlies it and the unpublished work that we present. Deciphering it is necessary for a correct interpretation of the groups and statues in which he represented male nudes or stripped heads, with which he always modified a space approaching the gender of the installation; or determined by involving the viewer through the attitudes, looks and complementary elements they carry.

Keywords: Carlos Montaño; painting; sculpture; Avant-Garde; Conceptual Art. 


\section{INTRODUCCIÓN}

La actividad de Carlos Montaño está parcialmente recogida en cinco catálogos que incluyen textos, todos muy breves, el primero con testimonios del propio artista $^{1}$; el segundo con varios muy reflexivos de Francisco del Río ${ }^{2}$, vinculado a una exposición celebrada en la galería Félix Gómez, Cuadros para encima de un sofá de sky rojo, en 1993; el tercero de nuevo de Francisco del Río ${ }^{3}$, para la exposición Carlos Montaño. En la orilla del cuerpo, en la Caja San Fernando de Sevilla, en 2002; el cuarto con uno de Braulio Ortiz ${ }^{4}$ y la repetición del anterior de Francisco del Río para la exposición El conflicto del objeto o la memoria de Dios, en 2016; y el quinto de Alberto Hevia ${ }^{5}$, debido a una exposición de pintura celebrada en la Galería Birimbao, Preludio, en 2018.

Entre unos y otros solo comentarios genéricos o la parte correspondiente en algún otro catálogo de exposición colectiva, como el de Ídolos. Esculturas, celebrada en la Galería Fausto Velázquez, en la que también participaron los escultores Miguel García Delgado (GEA) y Carlos Montaño, con texto de Francisco del Río ${ }^{6}$, en 1996; y, por supuesto, textos críticos en prensa, entre los que destacan los de Juan Bosco Díaz-Urmeneta, el más reciente dedicado a la exposición del año 2018 en la Galería Birimbao ${ }^{7}$, antes citada.

\section{UNA LARGA TRAYECTORIA Y UN FIRME CAMINO}

Carlos Montaño nació en Sevilla en el año 1956, e inició su formación artística en la década de los setenta. Se graduó en la Escuela de Artes Aplicadas y Oficios Artísticos de Sevilla, en la especialidad de Cerámica, en 1980; simultaneó los estudios y consiguió el título de licenciado en Bellas Artes, especialidad de Pintura, por la Universidad de Sevilla, en 1982; y celebró su primera exposición individual en la Galería Amadis, en Madrid, en 1983, con la colaboración del Ministerio de Cultura ${ }^{8}$. La siguiente fue $E l$ pecado, en el Colegio Oficial de Arquitectos de Sevilla, en 1985, en la que expuso pinturas, dibujos y cerámica9. Pronto obtuvo un premio en la I Muestra de Arte Contemporáneo Aduana, otorgado por la Diputación de Cádiz, en 1986.

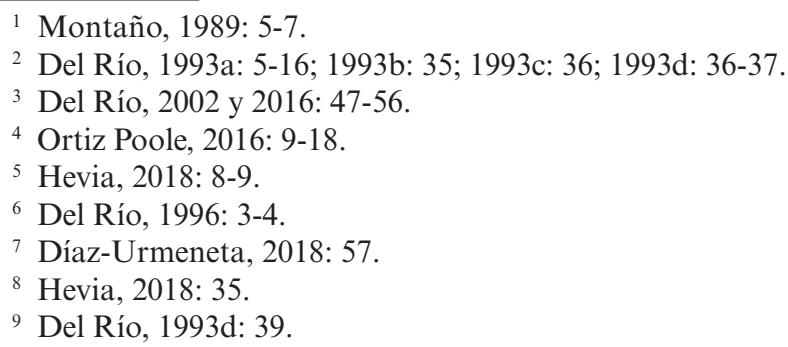


En 1987 obtuvo una beca de la Fundación Rodríguez-Acosta de Granada, en la especialidad de pintura, y consiguió el Primer Premio en el VIII Certamen Nacional de Pintura Ciudad de Utrera, el Primer Premio en el I Certamen Nacional de Pintura Renault, y una obra seleccionada en la sección de pintura en la Bienal de Países Mediterráneos. Ese año celebró dos exposiciones individuales: Sacrificios dorados, en la Galería Rafael Ortiz, y Fuera de comercio, en la Sala Sevilla, las dos en esta ciudad.

Ejerció como profesor de dibujo y expresión artística en la Extensión del Instituto de Bachillerato Pino Montano, desde 1988 hasta 2016. Los premios fueron muy frecuentes en los siguientes años: Primer Premio en el Certamen de Pintura Gustavo Bacarisas; Primer Premio en el IX Certamen Nacional de Pintura Ciudad de Utrera, los dos en 1988; y Primer Premio en el Certamen Nacional Pintores para el 92, convocado por el Monte de Piedad de Sevilla, en 1989. Al mismo tiempo, celebró las exposiciones individuales La cuadriga de Hermes, en la Sala E.U.A.T. de Sevilla, en 1988; El hombre de la Rosa, en la Galería Rafael Ortiz, en Sevilla; y Cuadernos de viaje, en la Sala Caja Postal de Cuenca, las dos en 1989; Marismas, en la Galería Parámetro de Santa Cruz de Tenerife, en 1990; y Serie 1991, de nuevo en la Galería Rafael Ortiz de Sevilla, en 1991. Un nuevo premio en el Certamen Hispano Americano de Pintura y Escultura Vázquez Díaz ratificó los éxitos en 1991.

En la siguiente exposición individual, planificada junto a Francisco del Río, Cuadros para encima de un sofá de sky rojo, en la Galería Félix Gómez de Sevilla, en 1993, presentó pinturas y esculturas. Ese año fue premiado en XLVI Certamen Nacional de Pintura José Arpa, en la ciudad de Carmona. En años sucesivos organizó exposiciones individuales en la Galería Benot de Cádiz, en 1994; Senda, dedicada a la acuarela, en la Galería Luis Verri de La Puebla del Río, en la provincia de Sevilla, y en la Galería Raquel Ponce de Madrid; Rutas de Occidente, en la Galería Félix Gómez de Sevilla, estas en 1995; y Pintura y esculturas, en la Galería Sandunga de Granada, en 1996. En la colectiva Ídolos, celebrada en la Galería Fausto Velázquez de Sevilla, expuso junto a los escultores Miguel García Delgado (GEA) y Carlos Tejedor. Obtuvo el I Premio en el IX Certamen Nacional de Esculturas Suso de Marcos, en Málaga, ese mismo año.

Ya era un pintor reconocido cuando fue becado por la Academia Española de Historia, Arqueología y Bellas Artes de Roma, en 1997. Esa temporada celebró dos exposiciones individuales, Pinturas, esculturas y dibujos, en la Galería Rafael Ponce de Madrid ${ }^{10}$; y El oído del Profeta, en la Galería Félix Gómez de Sevilla; y tuvo otra obra premiada en el XV Certamen Internacional de Pintura Eugenio Hermoso, en Fregenal de la Sierra, a la que siguió la premiada en el Certamen Nacional de Pintura de Gibraleón, en la provincia de Huelva, en 1998.

${ }^{10}$ Hevia, 2018: 35.

LABORATORIO DE ARTE 32 (2020), pp. 521-544, ISSN 1130-5762 e-ISSN 2253-8305 - DOI http://dx.doi.org/10.12795/LA.2020.i32.26 
Su presentación como escultor en la Galería Raquel Ponce de Madrid en 1997 coincidió con el desarrollo de nuevos estudios que culminaron con el título de licenciado en Bellas Artes, especialidad de Escultura, por la Universidad de Sevilla, en 1999. Ese año repitió la exposición individual, Pinturas, esculturas y dibujos, en la Galería Amasté de Bilbao. Finalizó el siglo con otra exposición individual, Dibujos y esculturas, en la Galería La Caja China de Sevilla, en 2000; e inició la nueva centuria repitiéndola con el mismo título en la Galería La Estampa de Madrid, en 2001. Adquirió una nueva proyección internacional con la exposición individual Cuadernos de Roma, celebrada en Ostia, en 2002. Ese año montó la itinerante En la orilla del cuerpo, que estuvo en la Caja San Fernando de Sevilla; Nerva, en la provincia de Huelva; y La Línea de la Concepción, en la provincia de Cádiz. Otra individual, Pinturas, esculturas y dibujos, lo llevó a la Galería Vali 30 de Valencia en 2003. Una beca a la creación artística contemporánea, en el marco del Proyecto Cádiz-La Habana de la Consejería de Cultura de la Junta de Andalucía, lo llevó a Cuba en 2005. De ese año es Limítrofe, la exposición individual que celebró en la Galería Félix Gómez de Sevilla. Nuevas exposiciones individuales, como Cádiz-La Habana. Pinturas y esculturas, en la Galería Sandunga de Granada; y La dársena de San Jerónimo, en la Galería Trocadero de Jerez de la Frontera, las dos en 2008, le permitieron mostrar sus experiencias cubanas de tres años antes y nuevas obras de ese período.

Continuó los estudios y obtuvo la licenciatura en Bellas Artes, especialidad de Grabado y Diseño, por la Universidad de Sevilla, en 2013. Le siguió su exposición El conflicto del objeto o la memoria de Dios, en la Casa de la Provincia de la Diputación de Sevilla, en 2017, y después en el Museo de Alcalá de Guadaíra e itinerante por toda la provincia ese año. En esta mostró también dibujos y grabados y obtuvo una gran resonancia en los círculos más cultos de la ciudad, lo que incentivó la publicación por parte del Área de Cultura y Ciudadanía de la Diputación de Sevilla del facsímil del Cuaderno de la Habana (de dibujos) en 2018. Esta coincidió con su última exposición individual hasta este momento, Preludio, en la Galería Birimbao de Sevilla.

A ese gran número de exposiciones, hay que añadir numerosas colectivas en Gijón, Sevilla, Cádiz, Barcelona, Utrera, Granada, León, El Puerto de Santa María, Madrid, Buenos Aires, Huelva, Pilas, Tomares, Coria del Río y Málaga, de ellas hasta nueve veces en Madrid y siete con la Galería Félix Gómez en Arco.

\section{LA LIEBRE COMO SÍMBOLO DE LIBERTAD}

Las primeras esculturas que Carlos Montaño presentó en público son las que mostró en la exposición Cuadros para encima de un sofá de sky rojo, en la Galería Félix Gómez de Sevilla, en 1993, seis años antes de su licenciatura en tal especialidad. 
Francisco del Río redactó un texto singular, muy reflexivo, en el que reflejó los testimonios del propio artista ${ }^{11}$. Este le dijo que en aquel momento planteaba su obra como una especie de desvelamiento de los sentidos, y el proceso creativo como un medio para dar forma como trasunto del sentido, de manera que este se convertía en un medio de reconsideración, esto es, en un camino de meditación. De esa manera, las formas apreciables en las pinturas y las esculturas de Carlos Montaño podían interpretarse como una continuidad material del proceso perceptivo $^{12}$, como un continuum en el que la acción se presenta como experiencia de un sujeto abierto, según Francisco del Río, no dogmático.

En el mismo texto, este autor afirmó que "toda actividad es auténtica cuando obedece a una necesidad interior y se preocupa por el efecto que produce; y consideró a Carlos Montaño como un sujeto indeciso y dubitativo que reflexiona sobre su papel y su obra en la década de los noventa, y en el seno las corrientes dominantes". Valoremos esas palabras: reflexión, duda y atención a los problemas de la pintura más avanzada y moderna de su tiempo, pueden entenderse como la problemática en torno a un posicionamiento plástico personal, caracterizado por el concepto analítico y la reacción propia, con la consiguiente toma de decisiones y respuestas en función de unas claves de época a las que dio respuesta así. No fue una crítica en el sentido peyorativo del término, sino el reconocimiento de una nueva actitud ante el arte, de un artista como sujeto de paso que asume su ser y su posición ante una situación y en un momento determinado, ni mejor ni peor y tampoco con vocación de certeza; mas sí propia, comprometida consigo mismo, con unos conceptos y una forma de ver la vida.

En otro texto, Francisco del Río reflexionó sobre esa actitud ante el Arte y la defensa de lo pictórico experimentada desde avanzada la década de los ochenta. Se centró fundamentalmente en las pinturas, que valoró como propias de una "tendencia formalista con gusto esteticista"13, en la que el estilo es la consecuencia de la expresión de un mundo individual. Teniéndolo en cuenta, propuso la división de las superficies en retículas como consecuencia de la influencia del Arte Pop y la Neofiguración sobre la abstracción. Vio en ello la ascendencia del espacio de la conciencia de Morandi, que estimó común a otros pintores sevillanos, cuyos nombres no precisó.

El sentido conceptual y genérico de los textos de Francisco del Río puede aplicarse a la exposición en general; mas no de modo específico a las esculturas. De hecho, en la entrevista que le hizo solo aparece una vez el término escultura, y fue para que Carlos Montaño afirmase que "sale a la par, y a la vez es lo mismo"14. A ello solo añadió una cuestión técnica sobre el modelado

\footnotetext{
11 Del Río, 1993b: 35.

${ }_{12}$ Del Río, 1993c: 36.

${ }^{13}$ Del Río, 1993d: 36-37.

${ }^{14}$ Del Río, 1993a: 11.
} 
íntegramente manual, sin uso de instrumento alguno. Hablaron sobre todo de la compartimentación de la superficie en rectángulos alternativos y de los elementos figurativos que aparecen en esos cuadro ${ }^{15}$. Solo algunas ideas comunes a la pintura pudieran servirnos como punto de partida para una correcta interpretación de las esculturas. Las más explícitas fueron la afirmación de la reducción de la experiencia visual a formas comunes depuradas, y la percepción no selectiva, que lo llevó al encuentro con la formas por analogía y gesto ${ }^{16}$.

Quedó pendiente el análisis técnico y formal de esas tres esculturas, en las que Carlos Montaño representó un conejo como elemento de bodegón supeditado a un espacio definido por un plato como base. Aunque el propio escultor reconoció su interés por ese espacio, lo hizo de modo genérico y más bien hablando de las pinturas, no de estas esculturas, cuya iconografía y relaciones formales no se trataron en el catálogo. La denominación Sin título de las tres y de todas las pinturas de la serie dificulta la identificación, que podemos hacer por la coincidencia del animal.

En una de ellas, Sin título ${ }^{17}$, del año 1993, representó al conejo suspendido en vertical e invertido, apoyado con la oreja derecha en la base del plato. La figura es análoga a la que ocupa el rectángulo central de una de las pinturas ${ }^{18}$. Por su fisonomía parece una liebre, tema muy representado por los pintores europeos de esa época como símbolo de la libertad y la superación de los obstáculos para conseguirla y mantenerla; sin embargo, tanto él como Francisco del Río hablaron de la representación de un conejo ${ }^{19}$. En cualquier caso, y pese a la relación antes indicada, Carlos Montaño mostró una clara afinidad con el escultor inglés Barry Flanagan, tanto en la composición como en el modelado manual, sin instrumentos, casi como trasunto de la escritura ${ }^{20}$.

Si la contemplamos de arriba hacia abajo se percibe el efecto de la gravedad, que indica la falta de impulso vital, como un animal muerto; si invertimos el punto de vista y la vemos de abajo hacia arriba, la sensación es otra, parece en equilibrio sobre la oreja derecha. El juego visual es muy sugerente, pues el cuerpo inerte del animal, muy evidente en la representación de la pintura indicada, cobra vida con la sensación de equilibrio y la relación espacial respecto de los límites del plato, como si reclamase un derecho que supera las acotaciones que lo limitan. Eso lo distingue del análogo pintado y lo relaciona como leve antecedente con las representaciones de los cuatro dibujos Sin título ${ }^{21}$, en los que el perro persigue a la

\footnotetext{
${ }^{15}$ Del Río, 1993a: 5-16.

${ }^{16}$ Del Río, 1993d: 37.

17 Bronce, $85 \times 30 \mathrm{~cm}$.

18 Óleo sobre cartón, 100 x $140 \mathrm{~cm}$.

19 Del Río, 1993a: 11.

${ }^{20}$ Del Río, 1993a: 11.

${ }^{21}$ Los cuatro, tinta sobre papel, 54 x $65 \mathrm{~cm}$.
} 
liebre y un corazón flota sobre ambos; la liebre lo coge pese a la persecución del perro; la liebre escapa y el corazón vuela; y la liebre a dos patas se descara y enfrenta con el perro como si fuese una persona.

El modelado de esa escultura es muy suelto, con rugosidades bien asimiladas como consecuencia de dejar visible el proceso de modo consciente, para que el churro de barro aplastado no compacte del todo, animando el modelado con la aparente indefinición de las superficies. Eso atendiendo a un concienzudo estudio de la anatomía del animal, interpretada con precisión y una intención somera muy sugerente. El sentido irónico coincide con Barry Flanagan, como también lo hace en Sin título ${ }^{22}$, en 1993, en la que aparece la liebre recostada, con las patas traseras recogidas con delicadeza humana, como si fuese una mujer en la playa (Figura 1). De nuevo es fundamental la relación espacial y el límite impuesto por el plato de base, cuyo espacio queda pequeño y justifica el escorzo. No es, pues, una liebre o conejo servido y listo para comer, sino la representación de un ser vivo y con aspecto inteligente, que nos observa desde su posición. La soltura del modelado es mucho mayor que en la anterior, y se acentúa en las zonas de los cuartos traseros humanizadas por la postura, en las que los pellizcos sobre el barro muestran la acción directa con naturalidad y modelado gestual eficaz.

Todo lo contrario que la tercera, también Sin título ${ }^{23}$, del mismo año 1993, esta vez sí, verdadera naturaleza muerta, en la que la cabeza de un conejo o liebre es un objeto más de bodegón, inerte y perfectamente alineado con dos churros de barro aplastados, que forman un eje sobre el plato marcando la relación espacial. El modelado es más prieto que en las anteriores; aunque en ningún modo perfilado y cerrado, solo lo suficiente para mantener la solemnidad de la presentación de la cabeza decapitada.

\section{LA SUBLIMACIÓN DE LA SENSUALIDAD: LA PRIMERA VERSIÓN DE EL PASEO DE SAN SEBASTIÁN, EN 1994}

Carlos Montaño modeló la estatua de tamaño académico El paseo de San Sebastián ${ }^{24}$ en 1994, por la que su propietario, el pintor y galerista Fausto Velázquez, sintió siempre una sincera admiración. Se trata de un ejemplar único, fundido en bronce en 1995.

El propio escultor le comentó a Francisco del Río su interés por el tema ${ }^{25}$. Impactado por el naturalismo del Descendimiento de Cristo de Caravaggio, y especialmente centrado en el humanismo del cuerpo en pleno descendimiento, reparó en un detalle concreto de un personaje secundario, San Sebastián, cuyo dedo toca

\footnotetext{
${ }^{22}$ Bronce, $30 \times 25 \mathrm{~cm}$.

${ }^{23}$ Bronce, $30 \times 25 \mathrm{~cm}$.

${ }^{24}$ Colección Fausto Velázquez. Bronce, tamaño académico.

${ }^{25}$ Del Río, 1993a: 12-13.
} 
la herida de Cristo con extrema sutilidad. Lo consideró un momento sublime, pues proyecta a un personaje situado en segundo plano en un primer nivel de interés, pleno de sensualidad.

Eso lo llevó a considerar la posibilidad del rito de la sensualidad. Para ello, adoptó la iconografía tradicional del santo, amarrado a un tocón de árbol y en pleno martirio, atravesado por plumas en vez de flechas. Lo que a simple vista sería una interpretación convencional es una representación sublime en la que aunó dos conceptos básicos, el tránsito momentáneo supeditado a la relación espacio-tiempo; y la sensualidad entendida desde un posicionamiento muy concreto, desde una identidad natural que insinúa más que desvela, $\mathrm{y}$, en tanto que tal, irrenunciable.

El suave contraposto y el organicismo de la anatomía en función de los delicados movimientos inducen a la percepción de una belleza formal cierta y que en ningún momento pretendió relegar y menos ocultar; sin embargo, ese no fue el propósito de Carlos Montaño, su intención prioritaria fue relacionarlo con el entorno, con el espacio en torno al eje que determina el árbol al que está amarrado. En esa secuencia espacio-tiempo, en la que el movimiento adquiere una extraordinaria delicadeza, es en la que manifiesta por completo su sensualidad, no en la belleza del cuerpo. El delicado contraposto es el medio por el que la anatomía se desplaza con sutilidad, con una sugerente desvelación de la identidad, confirmada con más ironía que ambigüedad por las plumas que se clavan en su cuerpo. No son las armas hirientes que mataron al santo, sino elementos de una realidad alternativa, de una condición revelada, que complementa la erótica de los desplazamientos con una relevante carga de sentido.

El paseo de San Sebastián de Carlos Montaño es mucho más que una escultura religiosa, es un símbolo, una seña de identidad que asume el legítimo orgullo de una naturaleza concreta, de un ser que está muy por encima de la narración de un pasaje, de la anécdota descriptiva. Es la sublimación de la sensualidad en un sentido amplio y pleno, desde una perspectiva en aquellos momentos alternativa y en la actualidad asumida y reconocida. Fue una manifestación valiente de la sensualidad otra y ahora es una interpretación cuya trascendencia intelectiva trasciende cualquier condicionante y puede apoyarse sin complejos en su belleza natural.

\section{ÍDOLOS, UNA POSICIÓN ALTERNATIVA EN ESPACIOS PROPIOS}

La participación de Carlos Montaño en la exposición colectiva Ídolos, junto a Miguel García Delgado (GEA) y Carlos Tejedor, celebrada en la Galería Fausto Velázquez de Sevilla entre los días 7 de junio y 5 de julio de 1996, le supuso la consideración junto a dos escultores acreditados y en igualdad de condiciones. 
Francisco del Río dio en la clave cuando afirmó que los tres escultores interrogaron lo antiguo para repensar lo nuevo ${ }^{26}$, entendido esto como una postura moderna y culta, que mantiene recuerdos nostálgicos de un brillante pasado y lo transforma renunciando a las circunstancias y los estilos originales. Nos advirtió de las composiciones en pequeño formato, en las que optó por la sugerencia de acciones en las que los símbolos fálicos, los animales heridos y la banalidad de los gestos inesperados transitan en espacios inaccesibles ${ }^{27}$. Con el tiempo volvió a insistir en el recuerdo de las referencias de la Antigüedad en un contexto inédito, muy actual ${ }^{28}$.

Veámoslo de modo específico en El hombre sagaz solo necesitó un gesto para comprender. Cuéntame tu historia ${ }^{29}$, del año 1996 (Figura 2). Es una instalación escultórica, pues el desnudo masculino, próximo al punto de partida del primero de los citados, se distancia y distingue de este por su condición indisoluble respecto del espacio en el que se inserta y significa. La postura, con el peso del cuerpo sobre la pierna izquierda e iniciando el paso con la derecha, muestra aún el torso erguido y vertical, propio de la fase de reposo de la que parte. La posición frontal de la cabeza contribuye a ello con sumo acierto. Con la mano derecha adelantada y el brazo levemente flexionado para propiciar el giro se sujeta el pene, utilizando apenas dos dedos, postura con la que muestra el glande con naturalidad. El brazo izquierdo cae paralelo al cuerpo, y con esa mano sujeta una cinta metálica, que asciende en la parte trasera superando la altura de la estatua con una potente y movida diagonal y pasa por debajo de los pies, describiendo otra diagonal hacia delante que voltea de nuevo quedándose a una distancia del cuerpo. La simplificación de la anatomía y la ausencia de elementos plásticos como el pelo centran la atención en los dos movimientos, el del cuerpo desplazado con extrema sutilidad y el de las cintas metálicas que vuelan libres a partir del mismo. Estas superan en mucho los límites del soporte cuadrangular e invaden y modifican el espacio real. La pequeña instalación asume el entendimiento referido a un estado natural que define la condición personal, proyectada por medio de la cinta metálica con total libertad. El gesto lo dice todo, y la cinta indica la superación de los límites.

Carlos Montaño ya había manifestado ese interés por el espacio ${ }^{30}$, y este es el protagonista de Se lo dijeron, pero advirtiéndole que estaba muy lejos y que a él llevaban dos caminos: uno por tierra y otro por mar ${ }^{31}$, en 1996 (Figura 3). El desnudo masculino parte del mismo original, con las variantes de la distinta posición

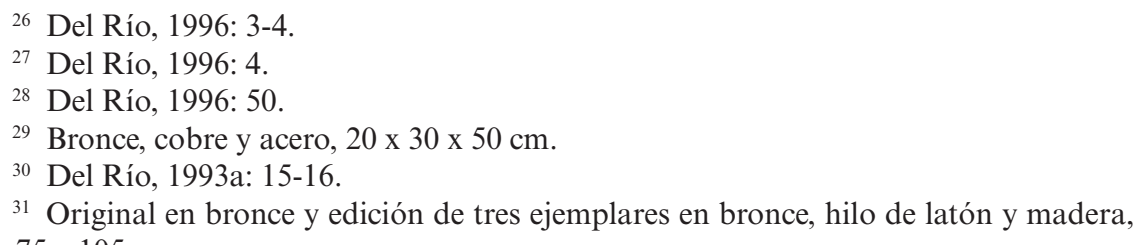
$30 \times 75 \times 105 \mathrm{~cm}$. 
de la cabeza, ahora elevada y levemente girada al lado derecho; y la posición del brazo derecho, en paralelo al cuerpo también y con la mano extendida y hacia afuera. Ese hombre, que puede ser cualquier hombre y no uno concreto, transita un espacio o campo con filamentos o cerdas metálicas alineadas en forma de áspero cepillo, que le cubren las piernas hasta casi la rodilla. La instalación ofrece distintos niveles conceptuales. El volumen significa y modifica un espacio determinado y ese transcurrir sobre un medio hostil alude a las dificultades del individuo en la vida que le tocó vivir y según las elecciones que hizo.

La figura es la misma en $Y$ parecía tan sumido en el éxtasis, que no hacía caso alguno de cuanto ocurría a su alrededor ${ }^{32}$, en 1996. Solo varían la posición de la cabeza, aquí frontal y levemente inclinada hacia abajo; y de la mano derecha, parecida a la anterior aunque en vertical hacia el suelo. Lo que verdaderamente le proporciona una identidad propia $y$, con esta, un sentido distinto es su relación con el espejo situado delante en la base, al que se asoma desde uno de los lados, ampliando infinitamente los horizontes de la instalación. El espectador no puede ver el reflejo de la imagen si no cambia de posición y lo contempla desde un punto de vista superior. Como en el grupo anterior, el desnudo masculino no significa en sí mismo, sino en cuanto ocupa un espacio que devuelve su imagen, utilizando el mito de Narciso para reflejar la necesidad de auto contemplación como medio de aceptación de su propia naturaleza. Esa era el éxtasis que lo aislaba en sí mismo y de la realidad otra en la que debía de convivir.

El parecido es aún mayor en Esto le agradó mucho y le incitó a explorar por arriba y por abajo hasta llegar a una cúpula, que le pareció llena de bendiciones ${ }^{33}$, también en 1996. El desnudo es análogo al de Se lo dijeron, pero advirtiéndole que estaba muy lejos y que a él llevaban dos caminos: uno por tierra y otro por mar, con la mínima variante de la cabeza, frontal como en El hombre sagaz sólo necesitó un gesto para comprender. Cuéntame tu historia. Esta vez, ese hombre genérico, tal vez él mismo también, está situado sobre una base rectangular y flanqueado por dos esferas de piedra, alusivas a dos mundos, para muchos ignotos, que una vez descubiertos y asumidos le proporcionan la felicidad. Si comparamos estos tres grupos, y los ponemos en orden, veremos que aluden a la aceptación de uno mismo, las dificultades que ello conlleva y la satisfacción que produce asumirlo con naturalidad, sin el mínimo complejo.

La titulada Torso ${ }^{34}$, del mismo año 1996, es muy distinta (Figura 4). Un torso masculino sobre un basamento en forma de rosca, muy bien proporcionado a diferencia de las anteriores, en las que ese concepto no era una prioridad, sirve de soporte a otras cinco, de izquierda a derecha de este un hombre sentado y girado

${ }^{32}$ Original en bronce y edición de siete ejemplares en bronce y cobre pulido, 10 x 20 $\mathrm{x} 30 \mathrm{~cm}$.

${ }^{33}$ Bronce, cobre y mármol, 10 x 20 x $30 \mathrm{~cm}$.

${ }^{34}$ Edición de cuatro ejemplares en bronce y uno en plata, $80 \times 50 \mathrm{~cm}$. 
hacia el interior, como las esculturas antiguas de los frontones y con un sentido primitivo distinto; un hombre desnudo caminando de frente, con la cinta alusiva a la libertad entre las manos; otro de espaldas, con las manos adelantadas y expectante a lo que pudiera venirle por detrás; y en el extremo derecho una mano auto determinante en la que se clava una aguja con la liebre que simboliza la libertad personal en plena carrera en el extremo superior. El discurso es complementario y el hombre sentado contempla dos realidades alternativas que dependen de sí mismo y deberá vivir en plena libertad de consciencia. Un cierto aire surrealista en la valoración del fragmento y las superposiciones de distintas figuras sobre el soporte de un torso con reminiscencias clásicas recuerdan a Igor Mitoraj ${ }^{35}$, con cuya estatua Cruise to Itaca, en 1993, comparte cierta carga de sentido.

\section{EL CONFLICTO DEL OBJETO O LA MEMORIA DE DIOS. LA IDEA RECUPERADA DE CAMINO Y PRESENCIA QUE LO TRANSITA, EN 2016-2019}

Carlos Montaño recuperó el concepto de espacio transitado y, como tal, vivido desde una óptica muy personal, tan íntima como la identidad de cada sujeto perceptivo capaz de afrontarlo, en una serie de pequeños grupos o instalaciones escultóricas de la segunda década del siglo XXI, que presentó en la exposición individual El conflicto del objeto o la memoria de Dios, celebrada en la Casa de la Provincia de Sevilla, en 2016.

Francisco del Río lo vio con su habitual claridad y profundidad, y detectó de modo temprano ese proceso de recuperación y reinterpretación de la vieja idea, advirtiendo la libertad de Carlos Montaño a la hora de modelar ${ }^{36}$; y, con esto, su completo desapego a las costumbres habituales en los talleres profesionales de escultura $^{37}$. Si lo volvemos a analizar y a pensar con la nueva perspectiva marcada por la evolución del escultor, podemos comprobar que esa despreocupación por la materia fue extensible a las formas canónicas de la Antigüedad, cuyo recuerdo mantuvo pese a todo, muy transformado, y se manifestaba ya como un rasgo morfológico propio, muy personal y excluyente, firme frente a las exigencias de la materia y la forma y las respuestas tanto tradicionales como modernas a los problemas que estas pudiesen plantear.

Braulio Ortiz Poole amplió esos análisis y mantuvo el elevado nivel en otro texto que inició con el examen de la pequeña instalación en la que aparece un

${ }^{35}$ Russel-Taylor, 1994: 13-19.

36 Del Río, 2016: 54.

${ }^{37}$ Por desgracia, la temprana y desgraciada muerte de Francisco del Río nos privó de un teórico del Arte fundamental en la proyección de las vanguardias artísticas sevillanas, de un pensador lúcido y profundo, gran entendedor de la pintura y la escultura de Carlos Montaño. 
Hombre sin cabeza $a^{38}$, y varias cabezas amontonadas delante. Francisco del Río las había llamado "cerro de cabezas" ${ }^{39}$, y dijo que entre ellas estaba la que le convenía al artista en ese momento por su edad y condición, relacionándola con El oído del profeta ${ }^{40}$, serie sobre Salomé de la que también proceden las cabezas cortadas, desgajadas del cuerpo, en las que propuso lecturas entrelazadas y complejas. Son las mismas que aparecen en tres dibujos Sin título ${ }^{41}$, en 2016.

En su texto, Braulio Ortiz Poole lo planteó como un individuo vulnerable que conecta con lo intangible y, a través de ese concepto, con la posibilidad de ser lo uno y lo otro, esto es, de ser múltiple. Esa multiplicidad puede verse en la dualidad que el artista planteó al sentirse uno como docente, otro como creador y otro en cada momento que lo exigiese. Según dicho teórico, Carlos Montaño no tuvo el deseo de recoger su realidad inmediata, sino planteó un hombre genérico desnudo y en esencia ${ }^{42}$. En definitiva, imágenes sugerentes que no responden a un concepto cerrado y por ello son interpretables. Eso contrasta con lo que Francisco del Río había anunciado unos años antes en relación con los grupos y las instalaciones previas, en las que pensó que Carlos Montaño no había eludido las referencias autobiográficas ${ }^{43}$.

Para Braulio Ortiz Poole la acción de Carlos Montaño es intelectiva y superior, pues el hombre genérico puede dejar atrás una cabeza y ponerse otra, transmitiendo una clara sensación de movimiento, serenidad y contención, sin que existan referencias externas que lo ubiquen en el espacio y el tiempo ${ }^{44}$, y tampoco a nosotros espectadores. A ello contribuye la renuncia a detallar las formas, optando por un modelado básico con el que propone una comunicación que el espectador está obligado a argumentar y completar. De ahí la falta de grandilocuencia y solemnidad, ausencias que estimó potenciadas por la sustitución de las peanas habituales en todo tipo de escultores por chapas simples.

Algo de esto puede verse en las instalaciones escultóricas Sin que las suelas toquen el suelo (Figura 5b), y Hombre apuntalado que carga con un corazón en su espalda, en 2015-2016. Si tenemos en cuenta la exigencia propuesta por Braulio Ortiz Poole, el primero, en el que un hombre carga con un caballo sobre sus hombros, pudiera asumir la representación simbólica del peso de la tradición clásica, revertido, puesto en un nuevo orden, el que corresponde a Carlos Montaño y no

\footnotetext{
${ }^{38}$ Ortiz Poole, 2016: 9.

39 Del Río, 2016: 50.

${ }^{40}$ Del Río, 2016: 51.

${ }^{41}$ Técnica mixta sobre papel, $112 \times 78 \mathrm{~cm}$. Técnica mixta sobre papel, $112 \times 78 \mathrm{~cm}$. Técnica mixta sobre papel, 39 x $28 \mathrm{~cm}$.

${ }^{42}$ Ortiz Poole, 2016: 10.

43 Del Río, 2016: 50.

${ }^{44}$ Ortiz Poole, 2016: 11.
} 
a las reglas de la Antigüedad; el otro, la de los sentimientos, humanos, personales, imperfectos si quieren verse así.

Esas posibilidades fundamentan el nuevo valor icónico de las cabezas masculinas de Carlos Montaño. El grupo titulado Dos cabezas, la instalación con una Cabeza pensativa sobre una escalera, y otros en los que aparecen agrupadas ante una figura, o en un pedestal ante una sola cabeza, como $Y$ yo pregunto (Figura 5a), en 2015-2017, serían la consecuencia inevitable de la intención advertida por Francisco del Río años antes, desde una experiencia en la playa de Ostia. Según dijo, parecen cabezas de la Antigüedad ${ }^{45}$. Carlos Montaño las dotó ahora con una nueva carga de sentido, incluida cierta relectura mitológica, que las sitúa en una línea comparable aunque distinta a la iniciada por Igor Mitoraj con estatuas como Blue Benarés ${ }^{46}$, en 1990.

Como también lo parece Pensador ${ }^{47}$, en 2008-2016. La pureza del desnudo masculino coincide con Miguel García Delgado (GEA) en El juego secreto, en 1984-1985; y el gesto con una mano en la sien con otra escultura del mismo, Hombre $N^{o} 4^{48}$, en 1992-1994; sin embargo, Carlos Montaño difiere de este en el relax del cuerpo, con todo el peso distribuido sobre ambas piernas en paralelo y, sobre todo, en la mirada al frente, inaccesible, determinando un recorrido visual que implica otro material inserto en el espacio físico del espectador. De ese modo, la estatua y el interceptor de su mirada interactúan de un modo distinto, más próximo al solemne distanciamiento de los desnudos masculinos de Antony Gormley. El recuerdo la Antigüedad nunca estuvo más cerca de Carlos Montaño y, al mismo tiempo, más lejos.

Braulio Ortiz Poole reconoció un cuerpo hiperrealista y el agudo contraste de los brazos como palillos y poliedros pentagonales por manos de la instalación escultórica en vitrina Sin título ${ }^{49}$, en 2008-2016. Las diferencias técnicas y formales son tan acusadas que advirtió un posible cambio de orientación en su escultura ${ }^{50}$, confirmado por el propio escultor ${ }^{51}$, que de momento no se ha producido. La pintura blanca sobre parte del torso aumenta la sensación de singularidad. Puede decirse que el cuerpo mantiene la pureza humanista de las obras anteriores, mientras que los brazos articulados y constructivos responden a la estética de los objetos encontrados y reaprovechados con un nuevo sentido estético, algo singular e inédito en su producción.

\footnotetext{
${ }^{45}$ Del Río, 1996: 53.

${ }^{46}$ Russel-Taylor, 1994: 48-49.

${ }^{47}$ Bronce, $46 \times 17$ x $15 \mathrm{~cm}$.

${ }^{48}$ Luque Teruel, 2017: 172-173.

49 Cera y elementos añadidos, 25 x 18 x $12 \mathrm{~cm}$.

${ }^{50}$ Ortiz Poole, 2016: 15.

${ }^{51}$ Testimonio aportado en persona al autor del artículo.
} 
La estatua El dibujante ${ }^{52}$, fechada en 2015-2016, presidió la agrupación de pequeñas instalaciones (Figuras 6 y 8a). Braulio Ortiz Poole destacó cómo resbala la luz por su cuerpo y el trasfondo mitológico de la granada que nos muestra con su mano izquierda ${ }^{53}$, mientras simula parar el aire con la derecha, con un gesto que tal vez indique paciencia. La talla en madera vista sí que supuso un nuevo punto de partida en la obra de Carlos Montaño, y no solo por el nuevo material y técnica, sino también por el tamaño natural de la estatua y por el refinamiento de la ejecución. Si antes no importaba la definición, los niveles de acabado, ahora son imprescindibles para un proceso de síntesis inédito en su obra. La extrema simplificación y delicadeza de las superficies mantiene el desinterés por la descripción del cuerpo de esculturas anteriores; mas lo hace de otro modo, manteniendo un orden estructural firme, refinado en extremo como medio para ascender a una comunicación intelectiva que trasciende los recuerdos de la Antigüedad y la Mitología conforme a los conceptos y las reglas personales que ya había avanzado.

El trabajo de síntesis es muy moderno y no tiene nada que ver con las fusiones del naturalismo esencialista del siglo XX. La fisonomía de El dibujante recuerda la silueta que nos muestra en un dibujo, Sin título ${ }^{54}$, en 2016, en la que significa bajo una estampa con la silueta de perfil de un perro sentado. La sonrisa de la estatua, distante, superior, parece hacernos cómplice de aquello que enuncia con la granada, según la mitología griega un tránsito feliz a una nueva vida que, en el pensamiento de Carlos Montaño, no tiene porqué ser ni metafísica, ni física, ni espiritual post mortem. La complicidad es hacia todo aquello que cada uno de nosotros pueda transitar con completa libertad, según sus condiciones, necesidades o simples circunstancias.

Lo que en El dibujante es calma y tranquilidad es tensión en El favor ${ }^{55}$, en 2016. Sea casualidad o no, la contorsión del desnudo masculino coincide con la de la escultora francesa Louise Bourgeois ${ }^{56}$ en la instalación Cells (Arch of histeria $)^{57}$, en 1992-1993; que repitió en Arch of histeria ${ }^{58}$, en 1993. El mismo escorzo lo repitió en los dibujos Sin título ${ }^{59}$, en 2016, apoyado en un palo y desdoblado por una sucesión de fuentes (urinarios) de Duchamp, que desdoblan el movimiento del cuerpo; y $\operatorname{Sin}_{\text {título }}{ }^{60}$, en el que aparecen dos elementos

\footnotetext{
52 Madera de tilo ensamblada, tallada y vista, 164 x 57 x $40 \mathrm{~cm}$.

53 Ortiz Poole, 2016: 12.

54 Técnica mixta sobre papel, $39 \times 28 \mathrm{~cm}$.

${ }^{55}$ Bronce, $12 \times 20 \times 7 \mathrm{~cm}$.

${ }_{56}$ Marshall, 1995a: 13-29. Herkenhoff, 1995: 31-41.

57 Marshall, 1995b: 86.

${ }^{58}$ Marshall, 1995b: 85.

59 Técnica mixta sobre papel, $112 \times 78 \mathrm{~cm}$.

${ }^{60}$ Técnica mixta sobre papel, $78 \times 112 \mathrm{~cm}$.
} 
simbólicos, el palo realista con el que simboliza el tiempo en sus pinturas, y las cabezas amontonadas. Debido al volumen real y al distinto criterio, la escultura de Carlos Montaño apoya las manos sobre la base metálica, arquea el cuerpo y apoya el pie derecho en el suelo, lejos de la base, mientras el izquierdo está a punto de hacerlo.

\section{PRESENTE Y FUTURO: EL PASEO DE SAN SEBASTIÁN, LA VERSIÓN DE 2019}

En la actualidad, Carlos Montaño prepara una nueva exposición bajo el tema de El paseo de San Sebastián, para la que ya ha pintado lienzos de gran formato en los que replantea y ofrece nuevas soluciones plásticas a la temática desarrollada en Preludio, la exposición individual celebrada en la Galería Birimbao de Sevilla, en 2018.

En esas pinturas aparecen los símbolos propios sobre campos informales, en los que destaca la presencia de la materia pictórica y la luz sobre tonos dorados que aluden a la trascendencia superior. En cada cuadro aparecen uno, dos o varios símbolos, que dan forma a la idea de tránsito como estado de ánimo en la concepción humana. Las espirales son el símbolo del ADN personal, la identidad de cada persona; el cubo abierto, la razón; el cubo cerrado, la memoria, siempre tan hermética; la percha, las dudas del hombre, innatas, necesarias también; el cardo, las dificultades, los contratiempos; los pies en uve, normalmente en la parte inferior, representan el cáliz, con cuanto este puede asumir en tanto esfuerzo necesario y consagración; las cintas, los límites, todos, cualquiera, según cada cuál; y la rama seca o palo, siempre tan reales en sus representaciones, el tiempo, su paso.

Con esas pinturas y compartiendo las claves simbólicas y la idea de espacio transitado, irán dos esculturas, la ya referida El dibujante, de 2015-2016, y una segunda versión del El paseo de San Sebastián ${ }^{61}$, que en estos momentos talla en madera de tilo (Figuras 7 y $8 b$ ). Esta tiene una altura de 1,88 metros y, como la anterior, irá en madera vista, y llevará algún elemento simbólico aún por decidir. El desnudo masculino, terminado ya, adquirirá mayor sentido con esos elementos, por lo que, pese a todo, se puede decir que todavía está en proceso creativo.

La nueva versión de El paseo de San Sebastián no tiene nada que ver formalmente con la del año 1994. Puede decirse que es una respuesta distinta a un mismo estímulo, la representación del espacio temporal en el que sucede algo importante. La síntesis del cuerpo se sustenta en una anatomía básica y precisa, excepcional en su alto grado de abstracción manteniendo claves orgánicas

${ }^{61}$ Madera de tilo ensamblada, tallada y vista, $1,88 \times 0,60 \times 0,60 \mathrm{~cm}$. 
fundamentales para su lectura. Esto y el gesto suave, la mirada cómplice, la extrema suavidad de las formas que lo relacionan directamente con El dibujante, centran nuestra atención y lo devuelven empáticamente hacia ese lugar que transforma con sus relaciones, ese no lugar que diría Francisco del Río en el que todo sucede y que es susceptible de compartir porque todos lo podemos identificar de un modo u otro en nuestras vidas.

Fecha de recepción: 30 de octubre de 2019

Fecha de aceptación: 23 de febrero de 2020

\section{BIBLIOGRAFÍA}

AA.VV. (2016): El conflicto del objeto o la memoria de Dios (catálogo). Sevilla: Diputación Provincial de Sevilla.

Del Río, Francisco (1993a): "Conversación Carlos Montaño-Francisco del Río". En: Montaño (catálogo). Sevilla: Galería Félix Gómez, pp. 5-16.

(1993b): "Una teoría del saber sensible". En: Montaño (catálogo). Sevilla: Galería Félix Gómez, p. 35.

(1993c): "La posibilidad de un saber práctico sin instrumentos: el artista como máquina o sujeto de paso”. En: Montaño (catálogo). Sevilla: Galería Félix Gómez, p. 36.

_(1993d): "La forma de los no-lugares". En: Montaño (catálogo). Sevilla: Galería Félix Gómez, pp. 36-37.

(1996): "La tarea”. En: Ídolos y esculturas (catálogo). Sevilla: Galería Fausto Velázquez, p. 53.

(2002): “Una conexión extraordinaria”. En: Carlos Montaño. En la orilla del cuerpo (catálogo). Sevilla: Caja de Ahorros San Fernando, pp. 47-56.

Díaz-Urmeneta, Juan Bosco (1998): "Un detenido ejercicio de pintura". En: Diario de Sevilla, 7-5-1988, p. 57.

Herkenhoff, Paulo (1995): "Algunas estancias de dolor y de deseo. El amor a la vida en la oba de Louise Bourgeois". En: Louis Bourgeois (catálogo). Méjico: Artes Gráficas Panorama, pp. 31-41.

Hevia, Alberto (2018): Preludio. Carlos Montaño (catálogo). Sevilla: Galería Birimbao.

Luque Teruel, Andrés (2017): Miguel García Delgado (GEA). El humanismo en la escultura contemporánea. Sevilla: Editorial Universidad de Sevilla.

Marshall, Richard D. (1995a): "Louise Bourgeois. Sobre sus temas". En: Louis Bourgeois (catálogo). Méjico: Artes Gráficas Panorama, pp. 13-30. (1995b): “Obras en exposición”. En: Louis Bourgeois (catálogo). Méjico: Artes Gráficas Panorama, pp. 43-89.

Montaño, Carlos (1989): Hombre de la rosa (catálogo). Sevilla: Galería Rafael Ortiz. 
Ortiz Pool, Braulio (2016): "Montaño y la inteligencia de los sentidos". En: AA.VV.: El conflicto del objeto o la memoria de Dios (catálogo). Sevilla: Diputación Provincial de Sevilla, pp. 9-18.

Russel-Taylor, John (1994): "Igor Mitoraj". En: AA.VV.: Igor Mitoraj. Sevilla: Caja de Ahorros San Fernando, pp. 42-49. 


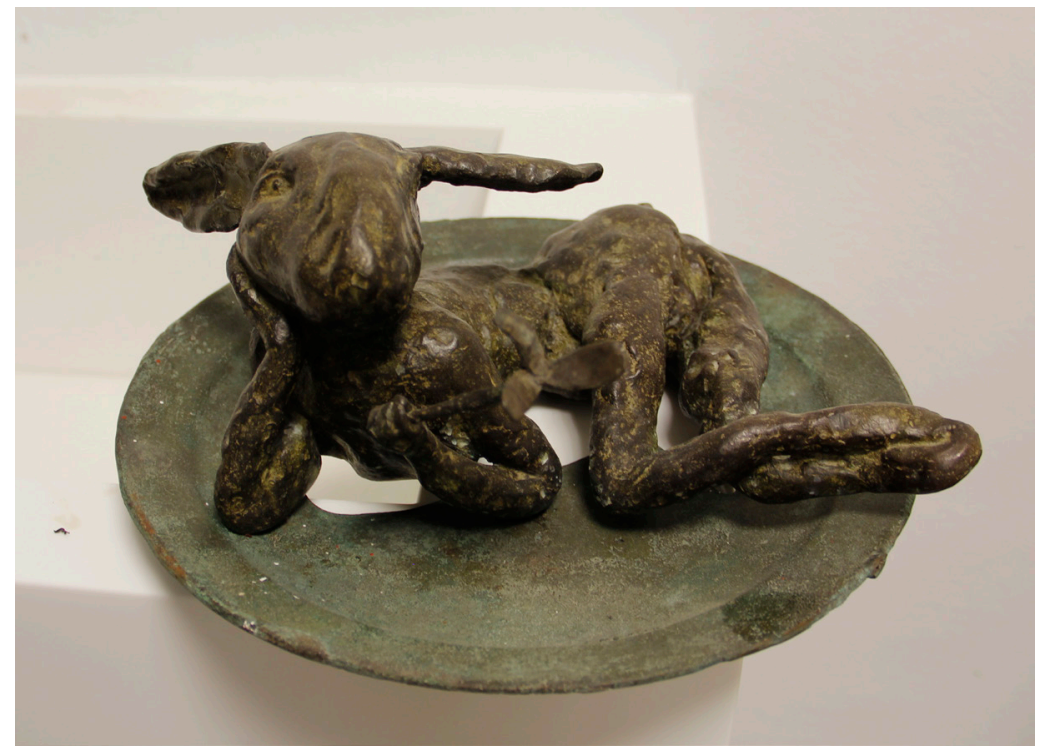

Figura 1. Carlos Montaño, Sin título, 1993, colección del artista. Foto: Alicia Iglesias Cumplido.

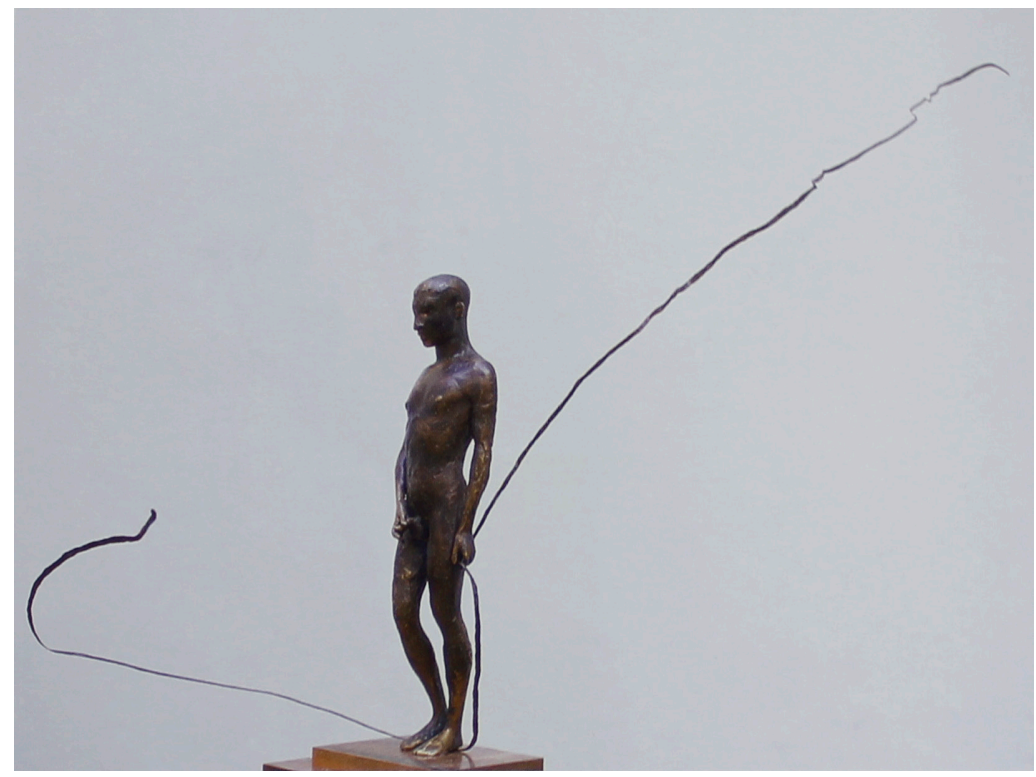

Figura 2. Carlos Montaño, El hombre sagaz solo necesitó un gesto para comprender. Cuéntame tu historia, 1996, colección particular. Foto: Alicia Iglesias Cumplido. 


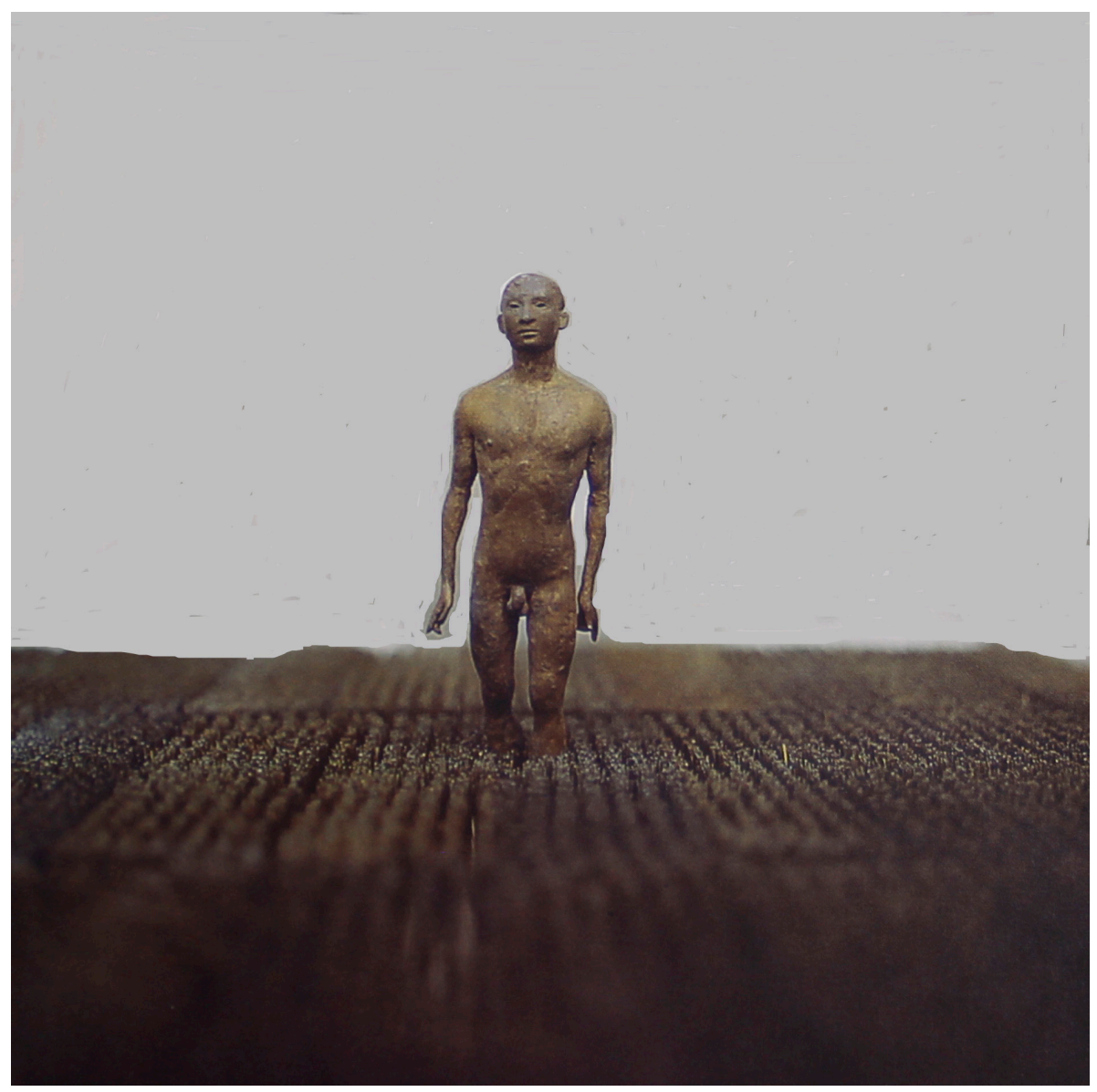

Figura 3. Carlos Montaño, Se lo dijeron, pero advirtiéndole que estaba muy lejos y que a él llevaban dos caminos: uno por tierra y otro por mar, 1996, colección particular. Foto: Alicia Iglesias Cumplido. 


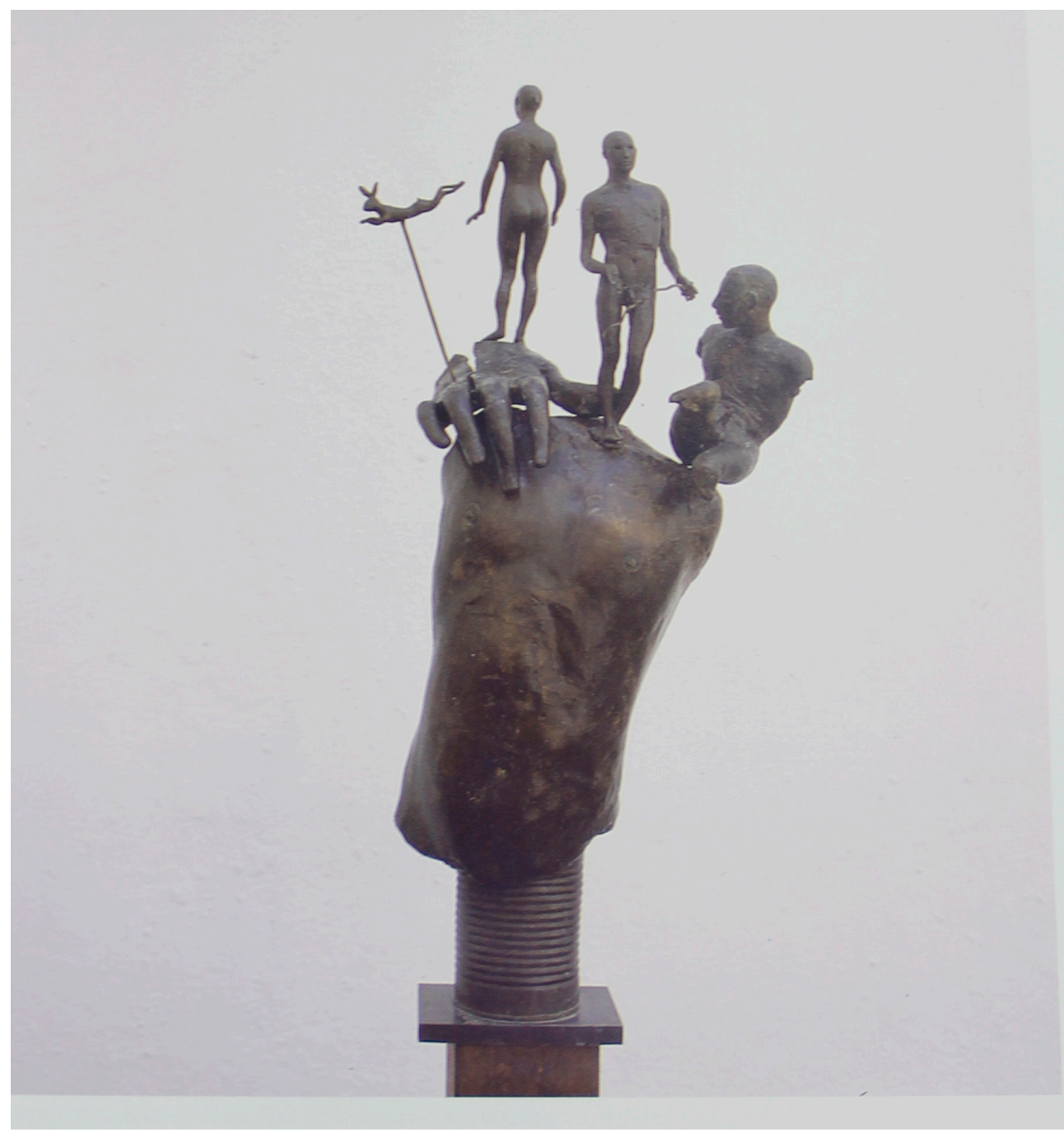

Figura 4. Carlos Montaño, Torso, 1996, colección del artista.

Foto: Alicia Iglesias Cumplido. 

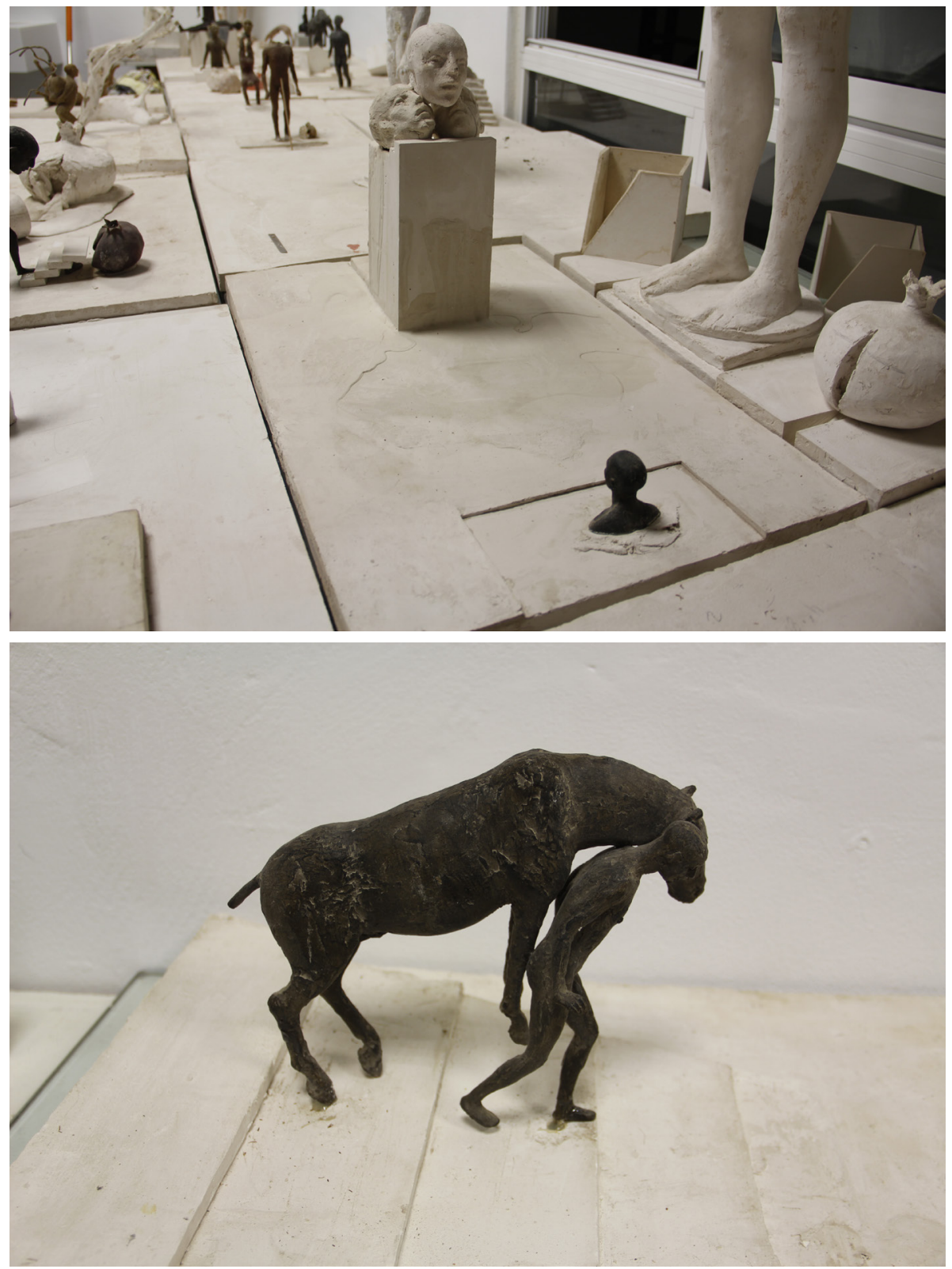

Figura 5. a) Carlos Montaño, Y yo pregunto, 2014-2016, colección del artista. Foto: Alicia Iglesias Cumplido. b) Carlos Montaño, Sin que las suelas toquen el suelo, 2014-2016, colección del artista. Foto: Alicia Iglesias Cumplido. 


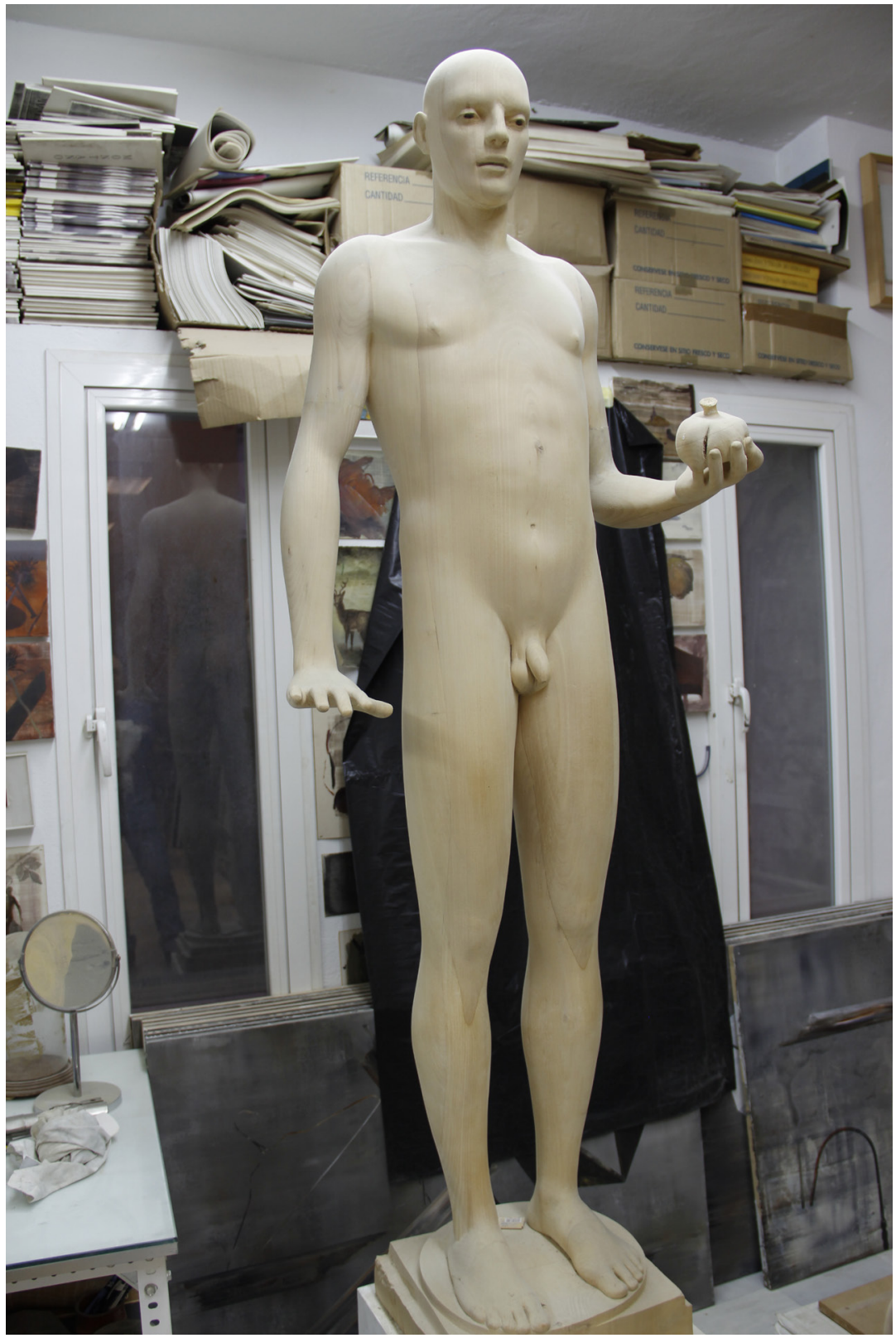

Figura 6. Carlos Montaño, El dibujante, 2015-2016, colección del artista. Foto: Alicia Iglesias Cumplido. 


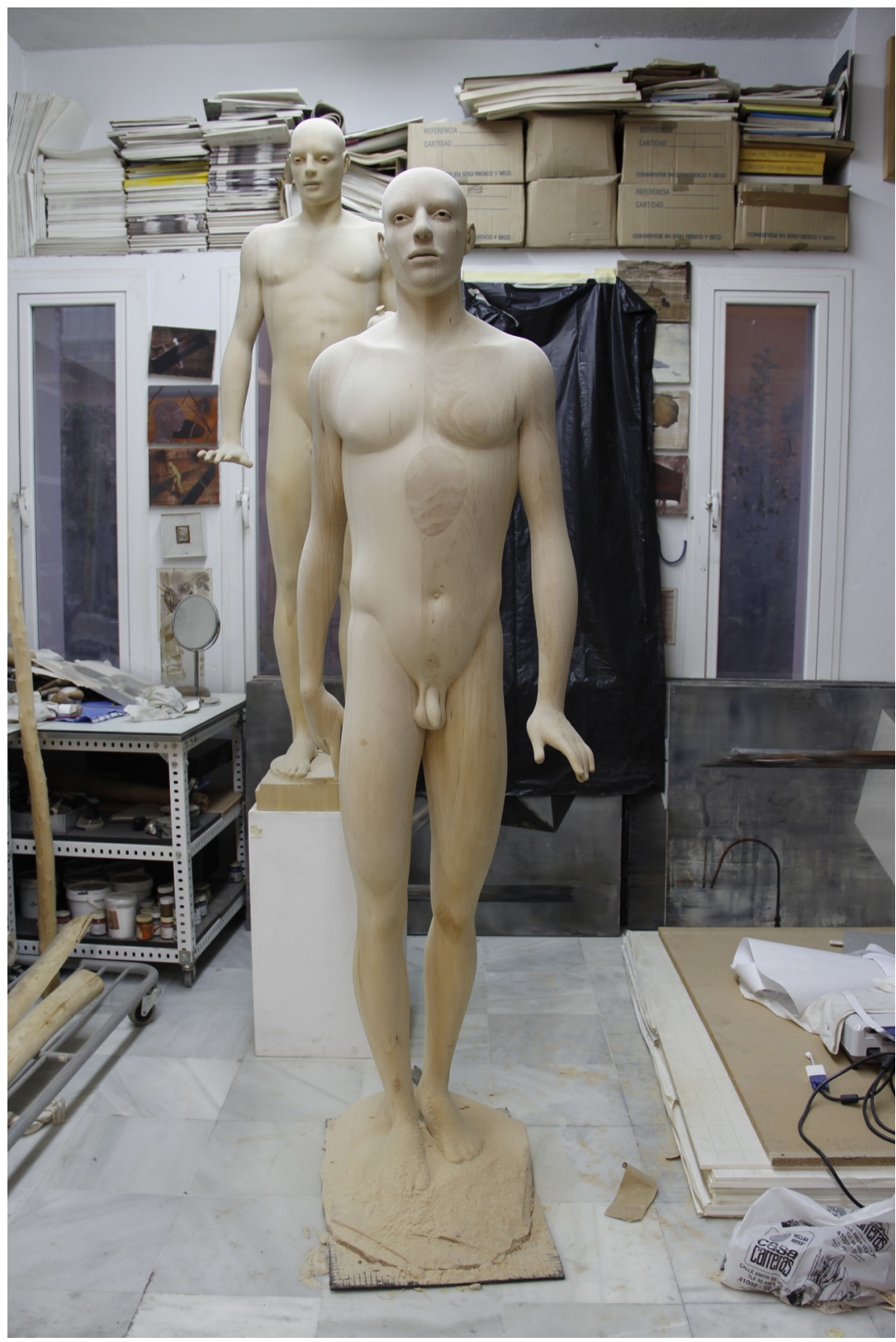

Figura 7. Carlos Montaño, El paseo de San Sebastián, 2019, colección del artista. Foto: Alicia Iglesias Cumplido. 

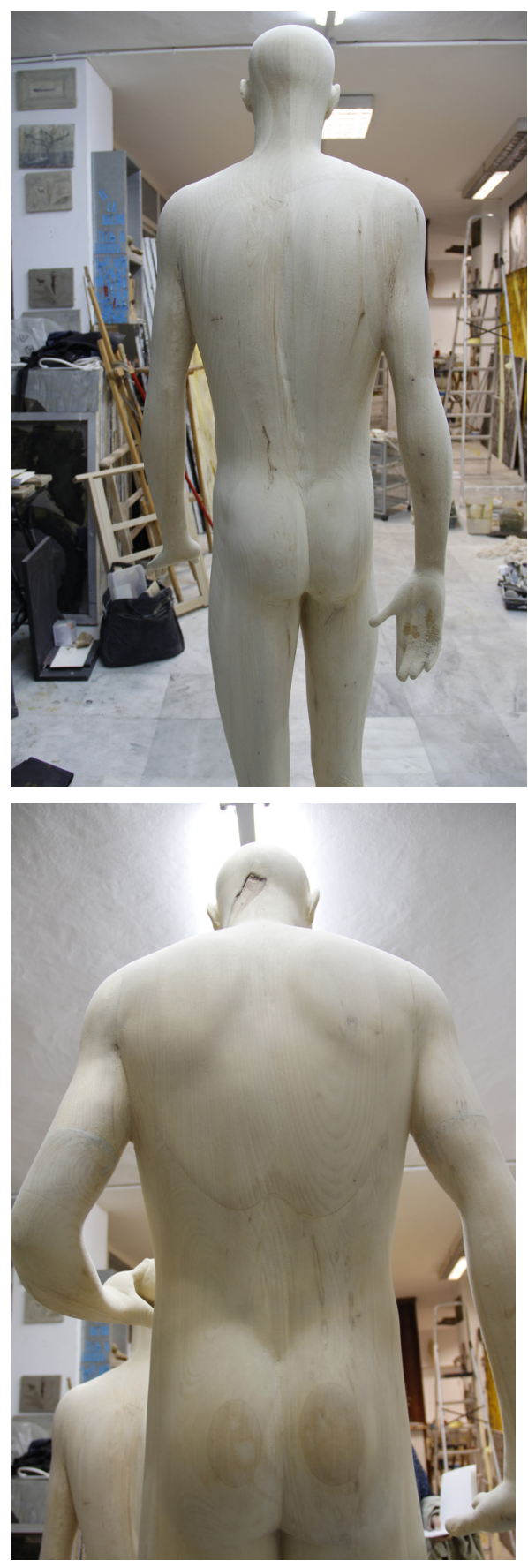

Figura 8. a) Carlos Montaño, El dibujante (dorso), 2015-2016. Foto: Alicia Iglesias Cumplido. b) Carlos Montaño, El paseo de San Sebastián (dorso), 2019, colección del artista. Foto: Alicia Iglesias Cumplido. 